\title{
Campylobacter fetus subspecies venerealis meningitis associated with a companion dog in a young adult: a case report
}

Yeol Jung Seong ${ }^{1}$, Seung Hun Lee ${ }^{2}$, Eun Jin Kim', Young Hwa Choi ${ }^{1}$, Tae-Joon Kim³ ${ }^{3}$ Wee Gyo Lee ${ }^{4^{*}+}$ and Jung Yeon $\mathrm{HeO}^{1 *+}$ (D)

\begin{abstract}
Background: Campylobacter spp., common commensals in the gastrointestinal tract of animals, especially poultry, can cause acute gastrointestinal illness in humans through animal-to-human transmission. Although Campylobacter fetus, especially subspecies fetus, rarely leads to systemic infections such as bacteremia in immunocompromised patients, it is unclear whether Campylobacter fetus subspecies venerealis (Cfv) causes infectious diseases in humans.

Case presentation: A 28-year-old man with a history of chronic alcoholism visited the emergency department with weakness of the left extremities. The patient was clinically diagnosed with community-acquired bacterial meningitis. The organism from the blood culture was subsequently identified as Campylobacter fetus. On phylogenetic analysis, the $16 \mathrm{~S}$ rRNA sequence showed $99.93 \%$ similarity with other Cfv $16 \mathrm{~S}$ rRNA sequences. The patient had no exposure to identifiable sources except for close contact with a companion dog, which could have been a possible source of transmission.
\end{abstract}

Conclusions: This case suggests that Cfv could lead to human systemic infections such as meningitis and that companion animals, in addition to well-known animal hosts, could be sources of transmission.

Keywords: Bacterial meningitis, Campylobacter fetus subsp. venerealis, Companion animal, Zoonotic infectious diseases

\section{Background}

Campylobacter spp., a zoonotic pathogen found in a wide range of animals whose primary reservoirs are the intestinal tracts, usually cause diarrheal illness in humans [1]. Although the vast majority of cases of Campylobacter infection in humans are caused by Campylobacter jejuni

\footnotetext{
*Correspondence: weegyo@ajou.ac.kr; jyeon78@naver.com

tWee Gyo Lee and Jung Yeon Heo contributed equally to this work

1 Department of Infectious Diseases, Ajou University School of Medicine, 164 Worldcup-ro, Youngtong-gu, Suwon, Gyeonggi-do 16499, Republic of Korea

${ }^{4}$ Department of Laboratory Medicine, Ajou University School

of Medicine, 164 Worldcup-ro, Youngtong-gu, Suwon, Gyeonggi-do

16499, Republic of Korea

Full list of author information is available at the end of the article
}

or Campylobacter coli, Campylobacter fetus occasionally causes extraintestinal infections, such as bloodstream infection, rather than enteric disease [2]. Invasive $C$. fetus infection has a broad spectrum of clinical presentation from bloodstream infection without apparent localized infection to various types of localized infections, including infection of central nervous system (CNS), osteomyelitis, lung abscess, arthritis, and perinatal infection. Human C. fetus infection is uncommon and usually occurs in patients with immunosuppressed conditions or underlying diseases such as cardiovascular disease with valve abnormalities, liver disease, and diabetes mellitus. Two major subspecies of C. fetus have been described: C. fetus subsp. fetus (Cff) and C. fetus subsp. venerealis 
(Cfv) [3]. Human infections with a new subspecies of $C$. fetus were proposed to be caused by $C$. fetus subsp. testudinum, which has a reptilian origin [4]. Almost nearly all cases of $C$. fetus infection in humans are known to be caused by Cff, and little is known about human infections caused by $\mathrm{Cfv}$. We recently encountered a case of bacterial meningitis caused by $\mathrm{Cfv}$ in a young adult. The patient strongly denied having been in close contact with domestic animals or ingesting raw animal products. The route of transmission was suspected to be the frequent close contact with a companion dog, such as while kissing. We also performed a systematic review to enhance our understanding of human C. fetus infections of the central nervous system (CNS).

\section{Case presentation}

A 28-year-old man with a history of chronic alcoholism visited the emergency department owing to weakness in the left extremities. He was under treatment with an antiepileptic drug for the past 6 months since a traumatic subdural hemorrhage occurred during a fall down the stairs. At that time, he underwent facial nerve decompression for left-sided facial palsy due to ear bleeding and a temporal bone fracture. He complained of a 5-day history of myalgia and upper respiratory infection symptoms, such as coughing and sore throat. Initially, his vital signs were stable except for a body temperature of $38.6{ }^{\circ} \mathrm{C}$. He was responsive to the medical staff's questions, but his answers lacked fluency. Findings of a physical examination performed on arrival to the emergency room were unremarkable, and mild neck stiffness was observed during a neurological examination.

Baseline laboratory data of complete blood count showed leukocytosis (white blood cell [WBC] count, $15,090 / \mu \mathrm{L}$; neutrophils, $87.5 \%$; lymphocytes, $4.9 \%$ ) with mild C-reactive protein elevation $(2.08 \mathrm{mg} / \mathrm{dL})$. Since the patient's neck stiffness worsened and stupor was noted, a cerebrospinal fluid (CSF) analysis was performed. The CSF analysis showed pleocytosis (WBC count of 390/ $\mu \mathrm{L}$; polymorphonuclear leukocyte count, $60 \%$ ), high protein level $(161.3 \mathrm{mg} / \mathrm{dL}$; reference range, $15-40 \mathrm{mg} / \mathrm{dL})$, and low glucose level (30 mg/dL; reference range, $40-70 \mathrm{mg} /$ $\mathrm{dL}$ ) with a negative Gram stain. No focal lesions were observed on brain magnetic resonance imaging (Additional file 1: Fig. S1). Intravenous ceftriaxone (2 g every $12 \mathrm{~h}$ ) and vancomycin ( 1 g every $12 \mathrm{~h}$ ) as empirical antibiotic therapy were administered with intravenous dexamethasone, as the findings were suggestive of bacterial meningitis caused by Streptococcus pneumoniae or Neisseria meningitidis.

On day 6 of hospitalization, blood culture revealed Gram-negative bacilli growth in the aerobic and anaerobic bottles. On day 11 of hospitalization, the organism was identified as $C$. fetus. However, these organisms were not identified in the CSF culture. The CSF specimen was collected $6 \mathrm{~h}$ after prompt empirical antibiotic treatment. Doripenem (500 mg every $8 \mathrm{~h}$ ) was administered for 10 days until the meningitis symptoms completely resolved without neurological sequelae. The automated susceptibility test (VITEK2 system, bioMérieux, France) showed that the isolate was susceptible to erythromycin and ciprofloxacin. The patient regularly visited the outpatient clinic for 2 years, without recurrence of the meningitis. He stated that he had been raising a companion dog and denied contact with livestock animals such as cattle and sheep or ingestion of raw or undercooked meat.

To confirm the species and identify the subspecies of the isolated C. fetus sample, a sequence analysis of the $16 \mathrm{~s}$ rRNA gene was conducted using the polymerase chain reaction primers 27F $5^{\prime}$-AGA GTT TGA TCM

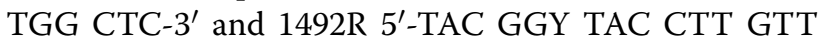
ACG ACT-3'. The sequencing primers 785F $5^{\prime}$ (GGA TTA GAT ACC CTG GTA) 3' and 907R 5' (CCG TCA ATT CMT TTR AGT TT) $3^{\prime}$ were used. The C. fetus $16 \mathrm{~S}$ rRNA sequence was compared to the published sequences from GenBank. Phylogenetic analysis (JukesCantor/Neighbor Joining) revealed that the 16S rRNA sequence in this case showed high similarity (99.93\%) with other Cfv 16S rRNA sequences (Fig. 1). These sequences were also distinct from those of Cff and other Campylobacter spp. compared with previously reported 16S rRNA nucleotides of other Campylobacter species (C, coli, C. jejuni, Cff) (Fig. 2).

\section{Discussion and conclusions}

Here we described a case of $C$. fetus meningitis in a young adult with a history of heavy alcoholism who was being treated with an antiepileptic drug for a traumatic cerebral hemorrhage. A culture isolate of $C$. fetus was identified as Cfv by sequence analysis of the 16s rRNA gene. C. fetus is divided into two major subspecies: Cff and Cfv [3]. These subspecies are genetically closely related but have different habitats and clinical importance. The primary reservoir of $\mathrm{Cff}$ is the intestinal tract of cattle and sheep [5]. Cff is a clinically significant pathogenic organism in animals and an opportunistic pathogen in humans. It has been identified in human cases of bloodstream infection, vascular infection, and cellulitis in addition to meningitis $[6,7]$. In contrast, $\mathrm{Cfv}$ is a commensal organism of the bovine genital tract that causes an infectious disease known as bovine genital campylobacteriosis, which leads to infertility and enzootic abortion in cattle, resulting in considerable economic losses [8]. Cfv has been isolated from human specimens in only a few cases [9], and its clinical significance remains uncertain. Thus, this is a rare case of systemic human infection caused by $\mathrm{Cfv}$. 

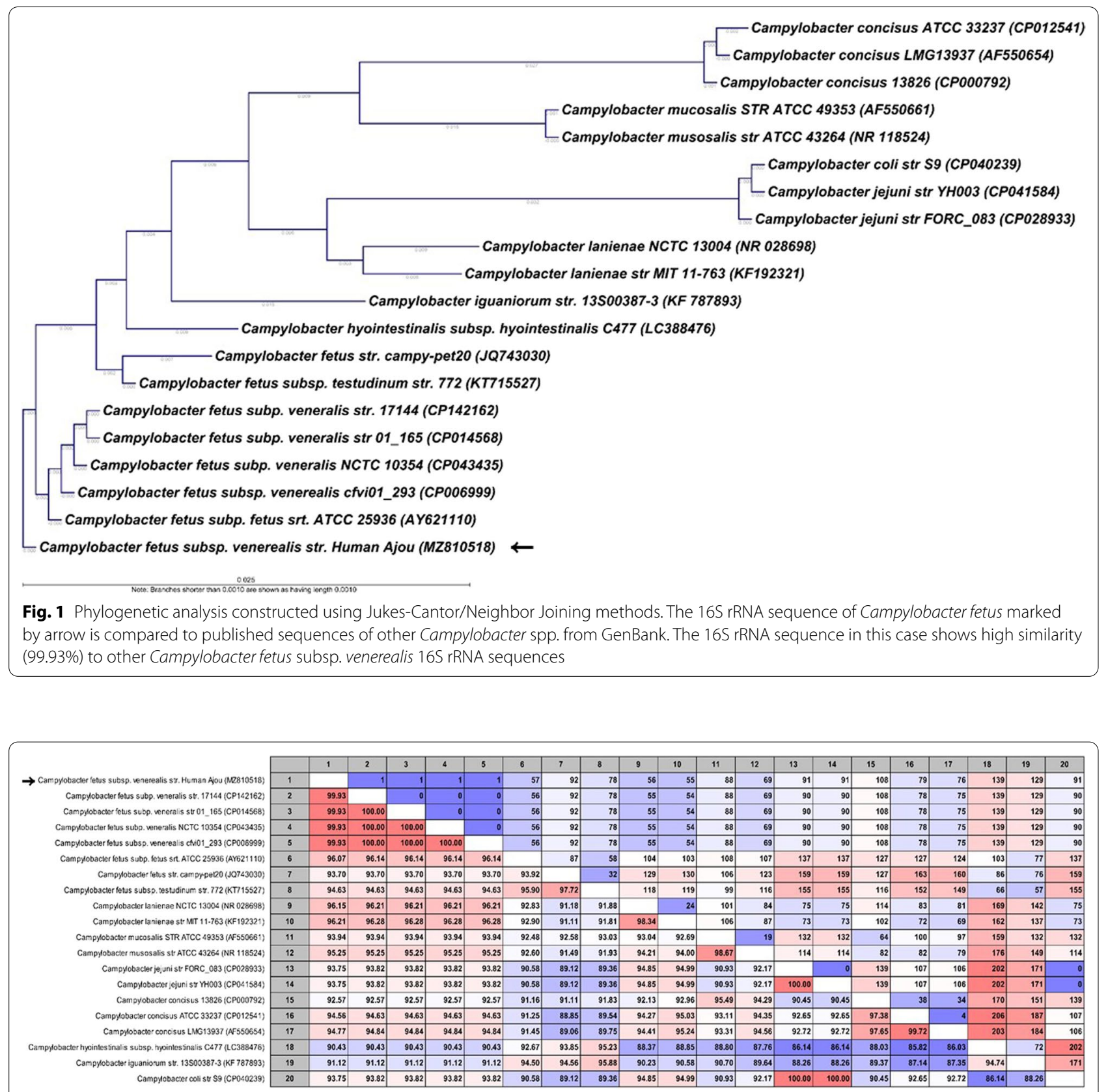

Fig. 2 Previously reported 16S rRNA nucleotides of other Campylobacter species. The 16S rRNA sequences of Campylobacter fetus subsp. venerealis marked by arrows are distinct from those of $C$. fetus subsp. fetus

To perform a systematic review for Campylobacter fetus meningitis, the MEDLINE database was searched using keywords Campylobacter fetus AND meningitis, Vibrio fetus AND meningitis, and Spirillum serpens AND meningitis. Literature written in English, French, German, Spanish, Japanese, and Korean were included. Case descriptions of animals or children were excluded. We identified 38 cases of CNS infections in 34 related articles published since 1960 (Table 1). Among these patients, 30 were men $(78.9 \%)$. The median age was 49.5 years (interquartile range, 39.8-57.0 years). Immunocompromised conditions were observed in 24 cases $(63.2 \%)$, and the prevalent underlying conditions were alcoholism (14 cases [36.8\%]) and diabetes (6 cases [15.8\%]). Although C. fetus is a zoonotic pathogen, the potential source of infection, such as animal or animal product contact, was 
Table 1 A case summary of Campylobacter fetus meningitis based on a systematic literature review

\begin{tabular}{|c|c|c|c|c|c|c|c|c|}
\hline Year $^{\text {Ref* }}$ & Age/Sex & $\begin{array}{l}\text { Underlying } \\
\text { condition }\end{array}$ & $\begin{array}{l}\text { Source of } \\
\text { infection }\end{array}$ & Specimens & (Sub)species & $\begin{array}{l}\text { Clinical } \\
\text { manifestations }\end{array}$ & Treatment & Outcome \\
\hline 2021 & $33 / F$ & ALL & $\begin{array}{l}\text { Undercooked } \\
\text { beef ingestion }\end{array}$ & Blood and CSF & Cf & Meningitis & MER & Recovery \\
\hline 2019 & $56 / \mathrm{M}$ & $\begin{array}{l}\text { Chronic alcohol- } \\
\text { ism }\end{array}$ & Unknown & CSF & Cf & $\begin{array}{l}\text { Meningoen- } \\
\text { cephalitis }\end{array}$ & AMP & Recovery \\
\hline 2019 & $35 / F$ & No & Unknown & Blood & Cf & $\begin{array}{l}\text { Meningitis and } \\
\text { spondylodiscitis }\end{array}$ & MEP, AMP & Recovery \\
\hline 2018 & $48 / F$ & No & $\begin{array}{l}\text { Raw beef and } \\
\text { cattle liver inges- } \\
\text { tion }\end{array}$ & CSF & $\mathrm{Cff} / \mathrm{Cfv}$ & Meningitis & $\mathrm{CRO}$ & Recovery \\
\hline 2017 & $64 / M$ & $\begin{array}{l}\text { Alcoholic liver } \\
\text { cirrhosis and } \\
\text { diabetes }\end{array}$ & Unknown & Blood & Cff & Meningitis & DOR & Recovery \\
\hline 2016 & $23 / F$ & No & $\begin{array}{l}\text { Domestic ani- } \\
\text { mals, worked on } \\
\text { a farm }\end{array}$ & CSF & Cf & Meningitis & CRO, MER & $\begin{array}{l}\text { Cured after } \\
\text { relapse, cognitive } \\
\text { defect }\end{array}$ \\
\hline 2016 & $52 / \mathrm{M}$ & No & Farmer & Blood and CSF & Cff & Meningitis & CRO, MER & Cured after relapse \\
\hline 2013 & $75 / \mathrm{M}$ & Diabetes & $\begin{array}{l}\text { Raw sheep liver } \\
\text { ingestion }\end{array}$ & Blood and CSF & Cff & $\begin{array}{l}\text { Meningitis and } \\
\text { endocarditis }\end{array}$ & IPM, GEN & Recovery \\
\hline 2013 & $28 / \mathrm{M}$ & Seizure disorder & Khat chewing & Blood & Cff & Meningitis & $\mathrm{CRO}$ & Recovery \\
\hline 2009 & $40 / \mathrm{M}$ & Crohn's disease & Unknown & $\begin{array}{l}\text { Blood, CSF, and } \\
\text { stool }\end{array}$ & Cf & Meningitis & PIP & Recovery \\
\hline 2008 & $51 / \mathrm{M}$ & No & Unknown & Blood and CSF & Cff & $\begin{array}{l}\text { Subdural empy- } \\
\text { ema }\end{array}$ & NA & Recovery \\
\hline 2006 & $43 / \mathrm{M}$ & No & Unknown & CSF & Cf & Meningitis & MER & Recovery \\
\hline 2004 & $71 / \mathrm{M}$ & Diabetes & Unknown & CSF & $\mathrm{Cff}$ & Meningitis & IPM & Recovery \\
\hline 2002 & $49 / M$ & $\begin{array}{l}\text { Chronic alcohol- } \\
\text { ism }\end{array}$ & Unknown & Blood and CSF & Cff & $\begin{array}{l}\text { Meningoen- } \\
\text { cephalitis and } \\
\text { spondylodiscitis }\end{array}$ & NA & Recovery \\
\hline 1998 & $47 / M$ & $\begin{array}{l}\text { Chronic alcohol- } \\
\text { ism }\end{array}$ & Dog and cat & Blood & Cff & Meningitis & CTX, OFX, GEN & Recovery \\
\hline 1997 & $70 / \mathrm{M}$ & $\begin{array}{l}\text { Chronic alcohol- } \\
\text { ism }\end{array}$ & Unknown & CSF & Cf & $\begin{array}{l}\text { Infected sub- } \\
\text { dural hematoma }\end{array}$ & IPM & Recovery \\
\hline 1996 & $84 / M$ & $\begin{array}{l}\text { Alcoholic liver } \\
\text { cirrhosis }\end{array}$ & Unknown & Blood and CSF & $\mathrm{Cf}$ & Meningitis & $\mathrm{CRO}, \mathrm{CIP}$ & Died \\
\hline 1993 & $40 / \mathrm{M}$ & No & Raw beef & Blood and CSF & $\mathrm{Cff}$ & Meningitis & IPM & Recovery \\
\hline 1990 & $55 / \mathrm{M}$ & $\begin{array}{l}\text { Chronic alcohol- } \\
\text { ism and diabetes }\end{array}$ & Unknown & CSF & Cf & Meningitis & AMP & Recovery \\
\hline 1989 & $39 / F$ & $\begin{array}{l}\text { Chronic alcohol- } \\
\text { ism, epilepsy }\end{array}$ & Unknown & Blood and CSF & Cff & Meningitis & AMS & Recovery \\
\hline 1989 & $36 / M$ & $\begin{array}{l}\text { Chronic alcohol- } \\
\text { ism }\end{array}$ & Unknown & Blood & $\mathrm{Cff}$ & Meningitis & AMP & Recovery \\
\hline 1987 & $47 / M$ & $\begin{array}{l}\text { Kidney trans- } \\
\text { plantation } \\
\text { recipient }\end{array}$ & $\begin{array}{l}\text { Raw cattle liver } \\
\text { ingestion }\end{array}$ & Blood and CSF & Cfi & Meningitis & ERY, CHL & Recovery \\
\hline 1986 & $30 / \mathrm{M}$ & No & $\begin{array}{l}\text { Raw cattle liver } \\
\text { ingestion }\end{array}$ & CSF & Cff & Meningitis & AMP & Recovery \\
\hline 1986 & $42 / M$ & No & Unknown & CSF & Cff & Meningitis & MIN & Recovery \\
\hline 1985 & $68 / M$ & $\begin{array}{l}\text { Rectal cancer } \\
\text { with hepatic } \\
\text { metastasis }\end{array}$ & Unknown & Blood and CSF & $\mathrm{Cff}$ & Meningitis & $\begin{array}{l}\text { CFZ, TOB, ERY, } \\
\text { AMP, GEN }\end{array}$ & Died \\
\hline 1985 & $65 / M$ & $\begin{array}{l}\text { Alcoholic liver } \\
\text { cirrhosis }\end{array}$ & Unknown & Blood & Cff & Meningitis & ERY & Cured after relapse \\
\hline 1985 & $38 / \mathrm{M}$ & $\begin{array}{l}\text { Chronic alcohol- } \\
\text { ism }\end{array}$ & Cat & CSF & Cff & Meningitis & AMP, GEN & Recovery \\
\hline 1984 & $53 / \mathrm{M}$ & No & Unknown & Blood and CSF & Cff & Meningitis & $\mathrm{CHL}$ & Recovery \\
\hline 1980 & $34 / \mathrm{M}$ & No & Unknown & CSF & Cff & Meningitis & $\mathrm{CHL}$ & Recovery \\
\hline
\end{tabular}


Table 1 (continued)

\begin{tabular}{|c|c|c|c|c|c|c|c|c|}
\hline Year $^{\text {Ref* }}$ & Age/Sex & $\begin{array}{l}\text { Underlying } \\
\text { condition }\end{array}$ & $\begin{array}{l}\text { Source of } \\
\text { infection }\end{array}$ & Specimens & (Sub)species & $\begin{array}{l}\text { Clinical } \\
\text { manifestations }\end{array}$ & Treatment & Outcome \\
\hline 1978 & $50 / \mathrm{M}$ & No & $\begin{array}{l}\text { Contact with } \\
\text { uncooked meat }\end{array}$ & Blood & Vf & Meningitis & $\mathrm{AMP}, \mathrm{CHL}$ & Recovery \\
\hline 1976 & $40 / M$ & No & $\begin{array}{l}\text { Frequent contact } \\
\text { with domestic } \\
\text { animal }\end{array}$ & CSF & Cfi & Meningitis & ERY, STM & Recovery \\
\hline 1971 & $53 / M$ & $\begin{array}{l}\text { Chronic alcohol- } \\
\text { ism }\end{array}$ & Unknown & Blood and CSF & Vf & $\begin{array}{l}\text { Meningoen- } \\
\text { cephalitis }\end{array}$ & AMP, KAN & $\begin{array}{l}\text { Comatose mental- } \\
\text { ity }\end{array}$ \\
\hline 1969 & $50 / \mathrm{M}$ & Diabetes & Unknown & CSF & Vf & Meningitis & PEN, AMP, CHL & Recovery \\
\hline 1969 & $69 / F$ & Diabetes, ITP & Unknown & Blood and CSF & Vf & Meningitis & PEN, CHL, SFZ & Died \\
\hline 1966 & $48 / F$ & No & $\begin{array}{l}\text { Farmer, cared for } \\
\text { sick calves }\end{array}$ & $\begin{array}{l}\text { Blood and peri- } \\
\text { cardial fluid }\end{array}$ & Vf & $\begin{array}{l}\text { Pericarditis and } \\
\text { meningitis }\end{array}$ & PEN, CHL & Hemiparesis \\
\hline 1964 & $55 / M$ & $C L L$ & $\begin{array}{l}\text { Rats at work- } \\
\text { place }\end{array}$ & Blood and CSF & Vf & Meningitis & PEN, TET & Recovery \\
\hline 1962 & $47 / M$ & $\begin{array}{l}\text { Chronic alcohol- } \\
\text { ism }\end{array}$ & Unknown & Blood and CSF & Vf & Meningitis & PEN, TET & Recovery \\
\hline 1960 & $50 / F$ & $\begin{array}{l}\text { Chronic alcohol- } \\
\text { ism }\end{array}$ & $\begin{array}{l}\text { Lived in rat- } \\
\text { infested neigh- } \\
\text { borhood }\end{array}$ & Blood and CSF & Ss & Meningitis & PEN, CHL & Recovery \\
\hline
\end{tabular}

* References for Campylobacter fetus meningitis are presented as Additional file 1

ALL, acute lymphoblastic leukemia; AMP, ampicillin; AMS, ampicillin/sulbactam; Cf, Campylobacter fetus; Cff, Campylobacter fetus subspecies fetus; Cfi, Campylobacter fetus subspecies intestinalis; Cf, Campylobacter fetus subspecies jejuni; Cfv, Campylobacter fetus subspecies venerealis; CFZ, cefazolin; CHL, chloramphenicol; CIP, ciprofloxacin; CLL, chronic lymphocytic leukemia; CRO, ceftriaxone; CSF, cerebrospinal fluid; CTX, cefotaxime; DOR, doripenem; ERY, erythromycin; GEN, gentamicin; IPM, imipenem; ITET, tetracycline; KAN, kanamycin; MEP, meropenem; MIN, minocycline; NA, not available; OFX, ofloxacin; PEN, penicillin; PIP, piperacillin; Ref, references; SFZ, sulfadiazine; Ss, Spirillum serpens; STM, streptomycin; TOB, tobramycin; TP, immune thrombocytopenic purpura; Vf, Vibrio fetus

identified in only 15 cases (39.5\%). Among the identified cases, the likely source of infection and the major risk factors for exposure to $C$. fetus were the ingestion of raw or undercooked meat (6 cases [40.0\%]) and frequent contact with animals (5 cases [33.3\%]).

This case shared common features of chronic alcoholism and frequent animal contact with the findings of the systematic review. In addition, the previous subdural hemorrhage in this case may have been a predisposing factor for meningitis. Potential disruption of the bloodbrain barrier could be a pathway for microbes to invade the central nervous system. However, other potential sources of infection were not identified, except for contact with the companion dog. We were unable to demonstrate that the dog was the source of transmission; however, given that $C$. jejuni transmission from a companion dog was genetically proven previously [10], the same is certainly plausible in this case. This case suggests that companion dogs could be a reservoir for zoonotic pathogens and their owners should be educated on zoonotic disease risk and prevention.

Systemic C. fetus infections, such as sepsis or meningitis, should be treated with parenteral antibiotics. Through a systematic review, we identified that most of the recently reported cases of C. fetus meningitis were treated with carbapenem antibiotics, similar to the present case. However, C. fetus is generally susceptible to ampicillin, cefotaxime, ciprofloxacin, aminoglycoside, and imipenem but not erythromycin [11]. Despite these patterns of antimicrobial susceptibility, C. fetus infection in the central nervous system should be treated with prolonged antibiotic treatment for at least 2-3 weeks [1]. The surface-layer proteins of C. fetus, critical factors in its virulence that form a capsule-like structure, can undergo antigenic variation that enables evasion of the host's immune system [12]. Therefore, an invasive C. fetus infection could relapse or persist even several years after the initial episode.

To the best of our knowledge, human $\mathrm{Cfv}$ infection has rarely been reported: We found only one case of an adult with meningitis and five cases of patients with bacteremia $[9,13]$. These human cases with $\mathrm{Cfv}$ infection were mainly identified by $16 \mathrm{~S}$ rRNA sequencing analysis. However, it could be difficult to differentiate between subspecies fetus and venerealis because of the modest subspecies-specific variation at the genome level [14]. A case of meningitis revealed that $\mathrm{Cff}$ and $\mathrm{Cfv}$ were verified through matrix-assisted laser desorption/ionizationtime of flight mass spectrometry (MALI-TOF-MD) and $16 \mathrm{~S}$ rRNA sequencing. Although five cases of bacteremia were identified as Cfv on the 16S rRNA sequencing analysis, three cases were identified as Cff and the other two cases were identified as Cfv by the multiplex PCR method using the $c a d \mathrm{~F}$, hip $\mathrm{O}$, and asp genes. Other 
bacteremia or meningitis cases attributed to C. fetus subspecies were mostly caused by Cff. The present case demonstrated that $\mathrm{Cfv}$ isolated from the blood has sequences distinct from Cff based on the 16S rRNA sequence and phylogenetic analysis.

Our case suggests that $\mathrm{Cfv}$ could cause human systemic infections, such as meningitis, and may be associated with companion animals in addition to well-known animal hosts.

\begin{abstract}
Abbreviations
ALL: Acute lymphoblastic leukemia; AMP: Ampicillin; AMS: Ampicillin/ sulbactam; C. coli: Campylobacter coli; C. fetus: Campylobacter fetus; C. jejuni: Campylobacter jejuni; Cf: Campylobacter fetus; Cff: Campylobacter fetus Subspecies fetus; Cfi: Campylobacter fetus Subspecies intestinalis; Cf: Campylobacter fetus Subspecies jejuni; Cfv: Campylobacter fetus Subspecies venerealis; CFZ: Cefazolin; CHL: Chloramphenicol; CIP: Ciprofloxacin; CLL: Chronic lymphocytic leukemia; CNS: Central nerve system; CRO: Ceftriaxone; CSF: Cerebrospinal fluid; CTX: Cefotaxime; DOR: Doripenem; ERY: Erythromycin; GEN: Gentamicin; IPM: Imipenem; ITET: Tetracycline; KAN: Kanamycin; MEP: Meropenem; MIN: Minocycline; NA: Not available; OFX: Ofloxacin; PEN: Penicillin; PIP: Piperacillin; Ref: References; rRNA: Ribosomal ribonucleic acid; SFZ: Sulfadiazine; WBC: White blood cell.
\end{abstract}

\section{Supplementary Information}

The online version contains supplementary material available at https://doi. org/10.1186/s12879-021-07007-5.

Additional file 1. Supplementary material.

\section{Acknowledgements}

Jin Sae Yoo and Young Rong Kim helped to obtain informed consent from the patient, and provided a feedback for case description. All authors thank for their assistance.

\section{Authors' contributions}

YJS and JYH contributed to the study conception and design. YJS, WGL, and $\mathrm{JYH}$ analyzed the data and take responsibility for its integrity and prepared the manuscript. All authors contributed to acquiring the clinical and laboratory data. YJS, SHL, EJK, YWC, TJK, WGL, and JYS contributed to the data analysis and interpretation. All authors critically revised the manuscript for intellectual content and approved the final draft for submission. All authors read and approved the final manuscript.

\section{Funding}

None.

\section{Availability of data and materials}

The 165 rRNA sequences of Campylobacter fetus subsp. venerealis are available in the GenBank database (Accession Number: MZ810518).

\section{Declarations}

Ethics approval and consent to participate

The study was conducted in accordance with institutional ethical guidelines.

The patient provided written informed consent to participate in the research.

\section{Consent for publication}

Written informed consent was obtained from the patient for the publication of this case report. A copy of the written consent is available for review by the editor of this journal.

\section{Competing interests}

The authors declare no competing interests.

\section{Author details}

${ }^{1}$ Department of Infectious Diseases, Ajou University School of Medicine, 164 Worldcup-ro, Youngtong-gu, Suwon, Gyeonggi-do 16499, Republic of Korea. ${ }^{2}$ Division of Infectious Disease Diagnosis Control, Honam Regional Center for Disease Control and Prevention, Korea Disease Control and Prevention Agency, Gwangju, Republic of Korea. ${ }^{3}$ Department of Neurology, Ajou University School of Medicine, Suwon, Republic of Korea. ${ }^{4}$ Department of Laboratory Medicine, Ajou University School of Medicine, 164 Worldcup-ro, Youngtong-gu, Suwon, Gyeonggi-do 16499, Republic of Korea.

Received: 23 August 2021 Accepted: 22 December 2021

Published online: 27 December 2021

\section{References}

1. Allos BM, lovine NM, Blaser MJ. Campylobacter jejuni and related species. In: Bennett JE, Dolin R, Blaser MJ, editors. Principles and practice of infectious diseases. Philadelphia: Elsevier Saunders; 2015. p. 2485-93.

2. Wagenaar JA, van Bergen MA, Blaser MJ, Tauxe RV, Newell DG, van Putten JP. Campylobacter fetus infections in humans: exposure and disease. Clin Infect Dis. 2014;58:1579-86.

3. van Bergen MA, Dingle KE, Maiden MC, Newell DG, van der Graaf-Van BL, van Putten JP, et al. Clonal nature of Campylobacter fetus as defined by multilocus sequence typing. J Clin Microbiol. 2005:43:5888-98.

4. Patrick ME, Gilbert MJ, Blaser MJ, Tauxe RV, Wagenaar JA, Fitzgerald C. Human infections with new subspecies of Campylobacter fetus. Emerg Infect Dis. 2013;19:1678-80.

5. Duncan JS, Leatherbarrow AJ, French NP, Grove-White DH. Temporal and farm-management-associated variation in faecal-pat prevalence of Campylobacter fetus in sheep and cattle. Epidemiol Infect. 2014;142:1196-204

6. Pacanowski J, Lalande V, Lacombe K, Boudraa C, Lesprit P, Legrand P, et al. Campylobacter bacteremia: clinical features and factors associated with fatal outcome. Clin Infect Dis. 2008;47:790-6.

7. Gazaigne L, Legrand P, Renaud B, Bourra B, Taillandier E, Brun-Buisson C, Lesprit P. Campylobacter fetus bloodstream infection: risk factors and clinical features. Eur J Clin Microbiol Infect Dis. 2008;27:185-9.

8. Silveira CDS, Fraga M, Giannitti F, Macias-Rioseco M, Riet-Correa F. Diagnosis of bovine genital campylobacteriosis in South America. Front Vet Sci. 2018;5:321.

9. Liu YH, Yamazaki W, Huang YT, Liao CH, Sheng WH, Hsueh PR. Clinical and microbiological characteristics of patients with bacteremia caused by Campylobacter species with an emphasis on the subspecies of C fetus. J Microbiol Immunol Infect. 2019;52:122-31.

10. Montgomery MP, Robertson S, Koski L, Salehi E, Stevenson LM, Silver R, Sundararaman P, Singh A, Joseph LA, Weisner MB, et al. Multidrug-resistant Campylobacter jejuni outbreak linked to puppy exposure - United States, 2016-2018. MMWR Morb Mortal Wkly Rep. 2018;67:1032-5.

11. Tremblay C, Gaudreau C, Lorange M. Epidemiology and antimicrobial susceptibilities of 111 Campylobacter fetus subsp fetus strains isolated in Québec, Canada, from 1983 to 2000. J Clin Microbiol. 2003;41(1):463-6.

12. Tu ZC, Gaudreau C, Blaser MJ. Mechanisms underlying Campylobacter fetus pathogenesis in humans: surface-layer protein variation in relapsing infections. J Infect Dis. 2005;191:2082-9.

13. Ishihara A, Hashimoto E, Ishioka H, Kobayashi H, Gomi H. Campylobacter fetus meningitis associated with eating habits of raw meat and raw liver in a healthy patient: a case report and literature review. IDCases. 2018;11:97-100.

14. Sprenger H, Zechner EL, Gorkiewicz G. So close and yet so far - Molecular Microbiology of Campylobacter fetus subspecies. Eur J Microbiol Immunol (Bp). 2012;2:66-75.

\section{Publisher's Note}

Springer Nature remains neutral with regard to jurisdictional claims in published maps and institutional affiliations. 